\title{
Bimonthly regimen of high-dose leucovorin, infusional 5-fluorouracil, docetaxel, and cisplatin (modified DCF) in advanced gastric adenocarcinoma
}

\author{
Ilkay Tugba Unek • Tulay Akman • \\ Ilhan Oztop • Olcun Umit Unal • Tarik Salman • \\ Ugur Yilmaz
}

Received: 17 June 2012/ Accepted: 9 October 2012/Published online: 22 October 2012

(C) The International Gastric Cancer Association and The Japanese Gastric Cancer Association 2012

\begin{abstract}
Background The combination of docetaxel, cisplatin, and 5 -fluorouracil (DCF) is an effective but highly toxic regimen for the treatment of advanced gastric cancer. To improve tolerability while maintaining the efficacy of the DCF regimen, we developed a modified DCF regimen including an infusional 5-fluorouracil administration according to the de Gramont regimen.

Methods In this study, 70 patients with advanced gastric cancer were treated. Each 2-week cycle consisted of docetaxel $\left(60 \mathrm{mg} / \mathrm{m}^{2}\right)$, cisplatin $\left(50 \mathrm{mg} / \mathrm{m}^{2}\right)$, a 5 -fluorouracil $\left(400 \mathrm{mg} / \mathrm{m}^{2}\right)$ IV bolus, and 5-fluorouracil $(2,400$ $\left.\mathrm{mg} / \mathrm{m}^{2}\right) \mathrm{IV}$ over $46 \mathrm{~h}$ plus leucovorin $\left(400 \mathrm{mg} / \mathrm{m}^{2}\right) \mathrm{IV}$ over $2 \mathrm{~h}$. Results The median progression-free survival and overall survival were 9.0 months (95\% CI, 7.1-10.9) and 10.8 months (95\% CI, 7.4-14.2), respectively; the 1-year and 2-year overall survival rates were 46.3 and $18.4 \%$, respectively. Twenty-nine (41.4\%) partial responses, 19 $(27.1 \%)$ stable disease, and $22(31.4 \%)$ progression of disease were observed. Grade 3-4 toxicities included neutropenia $(37.1 \%)$, febrile neutropenia $(15.7 \%)$, thrombocytopenia $(10.0 \%)$, anemia $(8.6 \%)$, nausea and vomiting $(10.0 \%)$, stomatitis $(5.7 \%)$, infection $(8.6 \%)$, and diarrhea $(2.9 \%)$.
\end{abstract}

I. T. Unek · T. Akman · I. Oztop · O. U. Unal · T. Salman

U. Yilmaz

Department of Internal Medicine, Division of Medical

Oncology, Dokuz Eylul University School of Medicine,

Izmir, Turkey

I. T. Unek ( $\square)$

Dokuz Eylul University Institute of Oncology,

35340 Balcova, Izmir, Turkey

e-mail: ilkaytugbaunek@gmail.com
Conclusions Our results show that a de Gramont-based DCF regimen may have tolerable toxicities and be an effective and convenient palliative treatment for advanced gastric cancer.

Keywords Advanced gastric cancer - Docetaxel · Cisplatin · Leucovorin · 5-Fluorouracil

\section{Introduction}

Gastric cancer remains one of the leading causes of cancer mortality worldwide [1]. In the treatment of advanced gastric cancer (AGC), no chemotherapy combination was accepted as the gold standard. Cisplatin plus 5-fluorouracil (CF) and epirubicin plus CF (ECF) regimens have been investigated widely in clinical studies and were, until recently, presented as the reference regimens [2-12]. The activity of docetaxel in gastric cancer was first demonstrated in phase II single-agent studies: reported overall response rates (ORRs) were 16-24\% in the first-line setting [13-17]. The combination of docetaxel and cisplatin (DC) as a first-line chemotherapy was revealed to have a modest anti-tumor effect and manageable toxicity for the palliative treatment of AGC [18-20].

A phase I/II dose-finding study demonstrated the feasibility of adding a protracted continuous infusion of 5-fluorouracil (5-FU) to DC (DCF) [21]. The subsequent three-arm, randomized, phase II study was conducted to compare firstline ECF, DC, and DCF regimens in patients with AGC. The results demonstrated ORRs of 25.0, 18.5, and $36.6 \%$ for ECF, DC, and DCF, respectively, and median survival durations of 8.3, 11.0, and 10.4 months, respectively [22].

In patients with AGC, the DCF triplet regimen appeared to be superior in terms of response rate to the doublet 
regimen of DC [23]. The subsequent phase III V325 trial was a randomized trial of first-line DCF versus CF in patients with AGC. This study showed that adding docetaxel to CF significantly improved progression-free survival (PFS) (5.6 months), overall survival (OS) (9.2 months), 1-year survival (40\%), 2-year survival (18\%), and ORR (37\%) compared with CF [24]. Despite a higher incidence of some toxicities as a result of the addition of docetaxel to $\mathrm{CF}$, the quality-of-life results of the V325 trial consistently favored DCF over CF, supporting the benefit of DCF [25]. Following the results of the V325 trial, the DCF has become a new reference regimen in AGC $[3,13]$. However, the toxicity profile of the DCF regimen has contributed to the limitations of using this combination. To improve tolerability while maintaining efficacy, several variations of the DCF regimen have either been reported or are currently under investigation, with different doses and administration schedules.

A bimonthly 2-day combination of leucovorin (LV) and 5-FU bolus plus continuous infusion (de Gramont regimen) permits a twofold increase in the dosage of 5-FU with less toxicity than the LV-5-FU bolus protocols, and this regimen increases the response rate in patients with colorectal carcinoma [26, 27]. The de Gramont regimen has also been investigated for the treatment of AGC either alone [28], in combination with cisplatin $[29,30]$, in combination with irinotecan [30, 31], in combination with cisplatin plus mitomycin-C [32], in combination with cisplatin plus epirubicin [33], or in combination with docetaxel plus cisplatin $[34,35]$. The results of these trials were encouraging in terms of both the safety profile and the activity.

In this study, we combined the de Gramont regimen with docetaxel and cisplatin, which was repeated every 2 weeks (modified DCF). The administration of the de Gramont regimen in combination with docetaxel and cisplatin has been previously reported by Tomasello et al. and Shah et al. [34, 35], but with only one 5-FU bolus, and a 46-h infusion of 5-FU in combination with cisplatin and docetaxel has not been previously reported. This study was planned to analyze the efficacy, toxicity, and convenience of a de Gramont-based DCF regimen as a first-line treatment in a larger number of patients with AGC.

\section{Patients and methods}

We retrospectively reviewed 133 chemotherapy-indicated patients with AGC at the Dokuz Eylul University School of Medicine, Division of Medical Oncology between 2005 and 2011. Seventy of these 133 patients examined were treated with the modified DCF regimen in this period. Eligibility criteria for modified DCF regimen included age $\geq 18$ years; measurable, unresectable, metastatic, or locally advanced gastric adenocarcinoma; Eastern Cooperative Oncology Group (ECOG) performance status $\leq 3$; no prior palliative chemotherapy; adequate hematological, renal, hepatic, and cardiac function; no other severe medical conditions; and no secondary malignancy. Each 2-week cycle consisted of docetaxel $\left(60 \mathrm{mg} / \mathrm{m}^{2}\right)$ IV on day 1 , cisplatin $\left(50 \mathrm{mg} / \mathrm{m}^{2}\right)$ IV with hydration on day $1,5-\mathrm{FU}$ $\left(400 \mathrm{mg} / \mathrm{m}^{2}\right)$ IV bolus, and 5 -FU $\left(2,400 \mathrm{mg} / \mathrm{m}^{2}\right)$ IV over $46 \mathrm{~h}$ plus LV $\left(400 \mathrm{mg} / \mathrm{m}^{2}\right)$ IV over $2 \mathrm{~h}$ on day 1 . A permanent venous access (port system) was implanted to enable a continuous infusion of 5-FU. For the prevention of chemotherapy-induced neutropenia, the patients were prophylactically administered a subcutaneous injection of granulocyte colony-stimulating factor (G-CSF) at a dose of $5 \mu \mathrm{g} / \mathrm{kg}$ on days $3,4,5,6$, and 7 . Treatment was repeated every 2 weeks until disease progression, patient refusal, or unacceptable adverse reactions occurred. All patients were fully informed regarding the treatment.

All the patients underwent a strict follow-up every 3 months. Before each cycle of chemotherapy, a complete blood count, blood urea nitrogen, electrolyte, and serum creatinine levels were obtained and liver function was determined. Dose reductions and delays of the mDCF regimen were implemented for patients with toxicities. The severity of the adverse effects was defined according to the National Cancer Institute Common Toxicity Criteria (NCI CTC). Toxicity from the chemotherapy was recorded by using hematological and biochemical parameters and by performing regular patient interviews. The medical records of these patients were retrospectively reviewed; the response evaluations and the side effects of the chemotherapy regimen were recorded. Response to treatment, defined by the Response Evaluation Criteria In Solid Tumors (RECIST), was evaluated by repeated computed tomography imaging every six cycles or earlier if clinically indicated. Doses of all drugs were reduced by $20 \%$ in subsequent cycles in the case of grade 3-4 hematological toxicities or grade 3-4 stomatitis or grade 3-4 nausea and vomiting. Doses of docetaxel and 5-FU were reduced by $20 \%$ in case of grade 3-4 diarrhea. Administration of cisplatin was stopped in case of grade $\geq 2$ peripheral neuropathy and grade $\geq 2$ nephrotoxicity where the glomerular filtration rate was less than $50 \%$ of the lower limit of normal. The administration of chemotherapy was delayed until neutrophils recovered $\left(\geq 1,500 / \mathrm{mm}^{3}\right)$ or platelets reached $\geq 100,000 / \mathrm{mm}^{3}$, or until resolution of any significant nonhematological toxicity. Treatment was interrupted for a recurrent grade 3-4 toxicity despite dose reduction.

Progression-free survival was defined as the time interval from the start of chemotherapy to the date of disease progression. Overall survival was calculated from the first day of treatment to death or the date of the last follow-up. Statistical analyses were performed with an SPSS program 
for Windows (version 15.0). The Kaplan-Meier method was used to estimate PFS and OS. $P$ values of 0.05 or less were considered statistically significant.

\section{Results}

Patient characteristics are listed in Table 1. The median age was 53.5 years (range, 33-74 years), with a male predominance $(68.6 \%)$. Sixty-three patients $(90.0 \%)$ had performance status 0 or 1 . Fifty-five patients $(78.6 \%)$ had metastatic disease at first diagnosis; the rest had recurrent disease. Ten patients $(14.3 \%)$ had received prior adjuvant chemotherapy. Six hundred and thirty-two cycles of chemotherapy were administered with a median of 10 cycles, ranging from 2 to 18 cycles. The most common disease sites were lymph nodes $(48.6 \%)$, peritoneum $(47.1 \%)$, liver (42.9\%), and lung (14.3\%).

Of the 632 cycles administered, dose reduction for at least one infusion was implemented for 33 patients (47.1\%) because of grade 3-4 toxicity, and dose delays were necessary in 40 patients $(57.1 \%)$. The toxicity profile is summarized in Table 2. The most common toxicities were hematological and gastrointestinal. Grade 3-4 neutropenia developed in 26 patients $(37.1 \%)$, and febrile neutropenia occurred in 11 patients $(15.7 \%)$. Seven patients $(10.0 \%)$ had grade 3-4 thrombocytopenia, and 6 patients $(8.6 \%)$ had anemia. The most commonly reported grade 3-4 gastrointestinal toxic effects were nausea and vomiting $(10.0 \%)$. Other nonhematological grade 3-4 toxicities included stomatitis (5.7\%), infection (8.6\%), and diarrhea $(2.9 \%)$. Cisplatin was discontinued in 1 patient because of grade 2 peripheral sensorial neuropathy and in 2 patients because of grade 2 nephrotoxicity. Docetaxel was discontinued in 1 patient for grade 2 skin toxicity. The treatment was interrupted in 12 patients $(17.1 \%)$ because of treatment-related toxic effects. Four deaths $(5.7 \%)$ occurred within 30 days of the last infusion. The main causes of treatment-related deaths were myocardial infarction (MI) in 3 patients and pneumonia in 1 patient.

Response rates with $\mathrm{mDCF}$ regimen are shown in Table 3. Twenty-nine (41.4\%) partial responses, 19 $(27.1 \%)$ stable disease, and $22(31.4 \%)$ progression of disease were observed. No complete response was recorded. The median progression-free survival time was 9.0 months [95\% confidence interval (CI), 7.1-10.9] and the 1-year and 2-year progression-free survival rates were 32.8 and $11.2 \%$, respectively (Fig. 1). The median overall survival time was 10.8 months (95\% CI, 7.4-14.2) and the 1-year and 2-year overall survival rates were 46.3 and $18.4 \%$, respectively (Fig. 2). Twenty-one patients $(30.0 \%)$ received second-line chemotherapy after failure
Table 1 Patient characteristics

\begin{tabular}{|c|c|c|}
\hline Characteristic & $n$ & Percent $(\%)$ \\
\hline \multicolumn{3}{|l|}{ Gender } \\
\hline Male & 48 & 68.6 \\
\hline Female & 22 & 31.4 \\
\hline \multicolumn{3}{|c|}{ Age, years (median, range) $53.5(33-74)$} \\
\hline \multicolumn{3}{|l|}{ ECOG performance status } \\
\hline $0-1$ & 63 & 90.0 \\
\hline $2-3$ & 7 & 10.0 \\
\hline Smoking & 37 & 52.9 \\
\hline \multicolumn{3}{|l|}{ Disease status } \\
\hline Newly diagnosed & 55 & 78.6 \\
\hline Relapses & 15 & 21.4 \\
\hline Prior gastrectomy & 15 & 21.4 \\
\hline Prior adjuvant chemotherapy & 10 & 14.3 \\
\hline \multicolumn{3}{|l|}{ Site of tumor } \\
\hline Cardia & 14 & 20.0 \\
\hline Corpus/fundus & 32 & 45.7 \\
\hline Antrum/pylorus & 24 & 34.3 \\
\hline \multicolumn{3}{|l|}{ Stage } \\
\hline Locally advanced disease only & 5 & 7.1 \\
\hline Distant metastases (M1) & 65 & 92.9 \\
\hline \multicolumn{3}{|l|}{ Number of metastatic sites } \\
\hline 1 & 26 & 37.1 \\
\hline 2 & 19 & 27.1 \\
\hline$\geq 3$ & 24 & 34.3 \\
\hline \multicolumn{3}{|l|}{ Metastasis site } \\
\hline Liver & 30 & 42.9 \\
\hline Lung & 10 & 14.3 \\
\hline Peritoneum & 33 & 47.1 \\
\hline Lymph node & 34 & 48.6 \\
\hline Second-line chemotherapy & 21 & 30.0 \\
\hline Living patients & 22 & 31.4 \\
\hline
\end{tabular}

ECOG Eastern Cooperative Oncology Group

Table 2 Grade 3-4 toxicities associated with chemotherapy

\begin{tabular}{lcc}
\hline Toxicity & $n$ & Percent $(\%)$ \\
\hline Neutropenia & 26 & 37.1 \\
Febrile neutropenia & 11 & 15.7 \\
Thrombocytopenia & 7 & 10.0 \\
Anemia & 6 & 8.6 \\
Nausea and vomiting & 7 & 10.0 \\
Stomatitis & 4 & 5.7 \\
Infection & 6 & 8.6 \\
Diarrhea & 2 & 2.9 \\
\hline
\end{tabular}

of this regimen. Of the 21 patients who received secondline chemotherapy, 17 patients received irinotecan-based chemotherapy and 4 patients received etoposide-based 
Table 3 Response rates with modified docetaxel, cisplatin, and 5-fluorouracil (DCF) regimen

\begin{tabular}{lcc}
\hline Response & Number of patients & Percent $(\%)$ \\
\hline Overall response & 29 & 41.4 \\
Complete & 0 & 0 \\
Partial & 29 & 41.4 \\
Stable response & 19 & 27.1 \\
Progressive disease & 22 & 31.4 \\
\hline
\end{tabular}

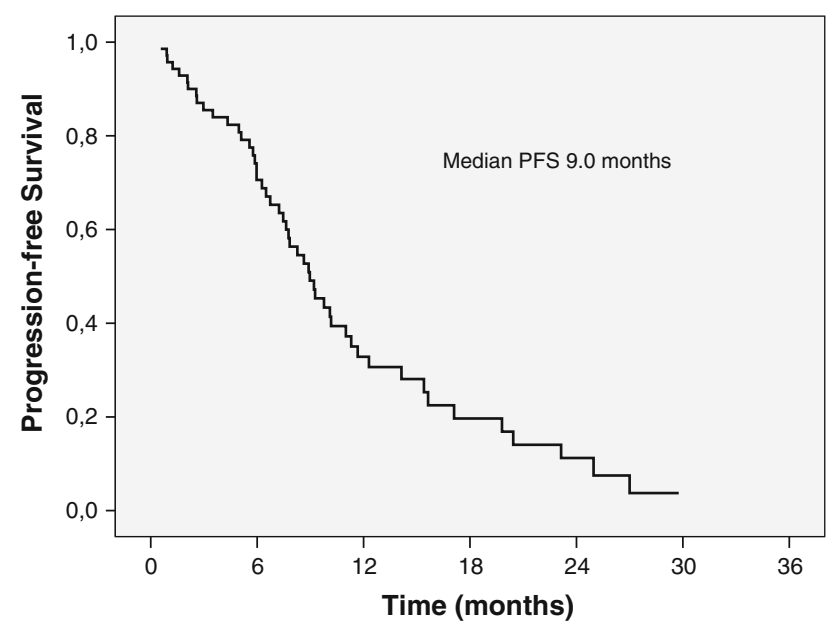

Fig. 1 Progression-free survival $(P F S)$ for all patients

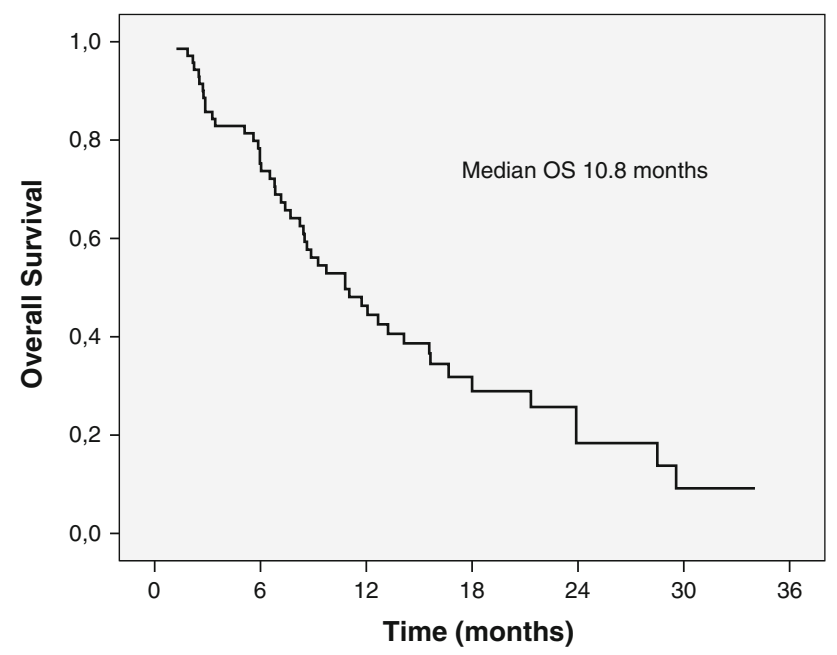

Fig. 2 Overall survival $(O S)$ for all patients

chemotherapy. During the study period, a total of 48 patients $(68.6 \%)$ have died.

\section{Discussion}

In light of the substantial toxicity of the DCF regimen, various attempts have been made to lessen its toxicity by modifying its dose and schedule. Herein, we investigated the de Gramont-based modified DCF regimen with the goal of minimizing toxicity without compromising efficacy. Our regimen demonstrated reasonable activity, with an ORR of $41.4 \%$, and a rate of stable disease of $27.1 \%$. The median PFS and OS were 9.0 and 10.8 months, respectively; the 1-year and 2-year overall survival rates were 46.3 and $18.4 \%$, respectively. The survival rates in our series were similar to those previously reported among patients with AGC using the standard DCF $[24,36]$. In the V325 trial, the median PFS and OS for DCF regimen were 5.6 and 9.2 months, respectively; the 1-year and 2-year survival rates were 40 and $18 \%$, respectively, with an ORR of $37 \%$. In that study, grade 3-4 neutropenia and febrile neutropenia were observed in 82 and $29 \%$ of patients, respectively. The chemotherapy regimen in our study was generally well tolerated. We have found that our $\mathrm{mDCF}$ regimen has a better toxicity profile when compared to the standard DCF regimen [24, 36]. In our study, we observed grade 3-4 neutropenia in $37.1 \%$ of patients and febrile neutropenia in $15.7 \%$ of patients. However, despite the promising safety data in our study, dose delays and dose reductions of one to two agents were required in 57.1 and $47.1 \%$ of patients, respectively. Considering that the complete blood count was done before each cycle in our study, the rate of neutropenia that usually appears after 7 days of docetaxel treatment could be higher than detected.

The number of deaths occurring within 30 days of the last infusion was $4(5.7 \%)$ in our study and $23(10 \%)$ in the V325 trial with the standard DCF regimen [24]. The main cause of toxic deaths was infection in the V325 trial. In our study, the rate of grade 3-4 neutropenia, febrile neutropenia, and grade 3-4 infection was lower than in the V325 trial since we administered prophylactic G-CSF. The common features of the three patients lost by MI in our study were existence of peritoneal metastasis and grade 3-4 nausea/vomiting associated with chemotherapy. We thought that hypovolemia, which occurred in the patients because of grade 3-4 nausea/vomiting, might induce MI. In addition, we thought that diffuse lung metastases and grade 3-4 neutropenia in the patient who died of pneumonia might have contributed to that patient's death.

The DCF regimen used by Roth et al. consisted of docetaxel $\left(75 \mathrm{mg} / \mathrm{m}^{2}\right)$ and cisplatin $\left(75 \mathrm{mg} / \mathrm{m}^{2}\right)$ on day 1 , plus protracted continuous infusion of 5-FU at a dose of $300 \mathrm{mg} / \mathrm{m}^{2} /$ day as a continuous infusion on days 1 to 14 , every 3 weeks [22]. In their study, the median OS was 10.4 months and ORR was $36.6 \%$. They observed grade 3-4 neutropenia and febrile neutropenia in 80 and $41 \%$ of patients, respectively. When compared to the DCF regimen with protracted infusion of 5-FU used by Roth et al., our de Gramont-based DCF regimen appears considerably more tolerable without compromising efficacy. 
Tomasello et al. conducted a phase II trial in 32 patients with AGC to evaluate for the first time the feasibility and activity of a modified DCF regimen, including an infusional 5-FU administration according to the de Gramont schedule [34]. This regimen consisted of docetaxel $\left(85 \mathrm{mg} / \mathrm{m}^{2}\right)$ on day 1 , cisplatin $\left(75 \mathrm{mg} / \mathrm{m}^{2}\right)$ on day $1, \mathrm{LV}\left(100 \mathrm{mg} / \mathrm{m}^{2}\right)$ on days 1 and 2, followed by 5 -FU $\left(400 \mathrm{mg} / \mathrm{m}^{2}\right)$ IV bolus on days 1 and 2 , and then 5 -FU $\left(600 \mathrm{mg} / \mathrm{m}^{2}\right)$ IV in continuous infusion of $22 \mathrm{~h}$, on days 1 and 2, every 2 weeks [34]. In their study, the most frequent grade 3-4 toxicities were neutropenia (53\%), thrombocytopenia (34\%), anemia (16\%), febrile neutropenia (22\%), asthenia (38\%), and diarrhea (19\%). The median PFS and OS were 9.1 and 10.1 months, respectively [34]. These researchers concluded that a dose-dense DCF regimen in AGC that was repeated every 2 weeks seems to be feasible, with activity comparable to previous results achieved with epirubicinbased chemotherapy and standard DCF regimens which were repeated every 3 weeks $[22,24]$.

As did Tomasello et al., Shah et al. also reported the de Gramont-based DCF regimen in 41 patients with AGC [35]. In that study, patients were randomly assigned to Arm A: de Gramont-based DCF (docetaxel $40 \mathrm{mg} / \mathrm{m}^{2}, 5-\mathrm{FU}$ $400 \mathrm{mg} / \mathrm{m}^{2}, \mathrm{LV} 400 \mathrm{mg} / \mathrm{m}^{2}$, 5 -FU $1,000 \mathrm{mg} / \mathrm{m}^{2} /$ day on days 1 and 2, cisplatin $40 \mathrm{mg} / \mathrm{m}^{2}$ on day 3, every 2 weeks), or Arm B: standard DCF [35]. The response rate of Arm A versus Arm B was 52 versus $34 \%$, respectively. The PFS was 8.6 months versus 7.1 months and the median OS was 15.1 months versus 12.6 months (Arm A vs. Arm B, respectively). Grade 3-4 neutropenia was 39 versus $40 \%$, febrile neutropenia 6 versus $17 \%$, nausea/vomiting 3 versus $20 \%$, and toxicity-related hospitalization 30 versus $53 \%$ (Arm A vs. Arm B, respectively). The authors concluded that the de Gramont-based DCF is an active and tolerable three-drug regimen.

Considering that the aim of treatment in metastatic disease is palliation, great importance should be given to the convenience and tolerability of the treatment. With only one 5-FU bolus and a 46-h infusion of 5-FU, our regimen appears easier and more convenient to administer than the standard [24] and dose-dense DCF regimens [34] and may increase the quality of life because of the short treatment duration. In our regimen, the dosages of docetaxel and cisplatin are lower than those dosages in the standard and dose-dense DCF regimens, which explains the low toxicity profile of our regimen.

Currently, many other studies that tested the different DCF regimens have been published [37-45]. The standard DCF regimen used by Van Cutsem et al. was a 5-day regimen. This regimen consisted of docetaxel at a dose of $75 \mathrm{mg} / \mathrm{m}^{2}$ and cisplatin at a dose of $75 \mathrm{mg} / \mathrm{m}^{2}$ on day 1 plus 5 -FU at a dose of $750 \mathrm{mg} / \mathrm{m}^{2} /$ day as a continuous infusion on days 1 to 5 , every 3 weeks [24]. Compared to the standard DCF regimen, requiring the patient to carry a 5-day continuous infusion pump once in each 21 days [24], our modified DCF regimen, which requires carrying a 2-day continuous infusion pump once in each 14 days, could be considered as a more convenient treatment. A 3-day continuous infusion schedule of 5-FU to reduce the infusion days of chemotherapy has been shown to be an active and tolerable regimen as a first-line treatment in patients with AGC [38]. A split-dose DCF regimen, with biweekly scheduling of docetaxel and cisplatin combined with weekly 5-FU and LV, has also been shown to be an active treatment with favorable toxicity profile in AGC [37]. Subsequent attempts have been tried to improve the tolerability of the DCF regimen by reducing or fractionating the doses of cisplatin and docetaxel [38-42]. Monthly DCF regimens [43] and weekly DCF regimens [44, 45] have been investigated as first-line therapy in patients with AGC. The results of these studies suggest that modification of the standard DCF schedule may yield a regimen with an improved safety profile, without compromising the efficacy of the regimen [38-45].

In summary, our results show that a de Gramont-based DCF regimen may have tolerable toxicities and be an effective and convenient palliative treatment of AGC. It may provide an alternative regimen to the standard DCF. Because of the bimonthly 2-day infusion schedule with only one 5-FU bolus, this regimen can be administered on an outpatient basis without disrupting daily life. Future trials of palliative chemotherapy for AGC using the de Gramont-based DCF regimen are needed.

\section{References}

1. Jemal A, Bray F, Center MM, Ferlay J, Ward E, Forman D. Global cancer statistics. CA Cancer J Clin. 2011;61(2):69-90.

2. Wagner AD, Grothe W, Haerting J, Kleber G, Grothey A, Fleig WE. Chemotherapy in advanced gastric cancer: a systematic review and meta-analysis based on aggregate data. J Clin Oncol. 2006;24:2903-9.

3. Van Cutsem E, Van de Velde C, Roth A, Lordick F, Köhne CH, Cascinu S, et al. Expert opinion on management of gastric and gastro-oesophageal junction adenocarcinoma on behalf of the European Organisation for Research and Treatment of Cancer (EORTC)-gastrointestinal cancer group. Eur J Cancer. 2008;44: 182-94.

4. Kim NK, Park YS, Heo DS, Suh C, Kim SY, Park KC, et al. A phase III randomized study of 5-fluorouracil and cisplatin versus 5-fluorouracil, doxorubicin, and mitomycin $\mathrm{C}$ versus 5-fluorouracil alone in the treatment of advanced gastric cancer. Cancer (Phila). 1993;71(12):3813-8.

5. Webb A, Cunningham D, Scarffe JH, Harper P, Norman A, Joffe $\mathrm{JK}$, et al. Randomised trial comparing epirubicin, cisplatin, and fluorouracil versus fluorouracil, doxorubicin, and methotrexate in advanced esophagogastric cancer. J Clin Oncol. 1997;15(1): 261-7. 
6. Ross P, Nicolson M, Cunningham D, Valle J, Seymour M, Harper $\mathrm{P}$, et al. Prospective randomised trial comparing mitomycin, cisplatin, and protracted venous infusion fluorouracil (PVI 5-FU) with epirubicin, cisplatin, and PVI 5-FU in advanced esophagogastric cancer. J Clin Oncol. 2002;20(8):1996-2004.

7. Findlay M, Cunningham D, Norman A, Mansi J, Nicolson M, Hickish T, et al. A phase II study in advanced gastroesophageal cancer using epirubicin and cisplatin in combination with continuous infusion 5-fluorouracil (ECF). Ann Oncol. 1994;5: 609-16.

8. Bamias A, Hill ME, Cunningham D, Norman A, Ahmed FY, Webb A, et al. Epirubicin, cisplatin, and protracted venous infusion of 5-fluorouracil for esophagogastric adenocarcinoma: response, toxicity, quality of life, and survival. Cancer (Phila). 1996;77:1978-85.

9. Waters JS, Norman A, Cunningham D, Scarffe JH, Webb A, Harper $\mathrm{P}$, et al. Long-term survival after epirubicin, cisplatin and fluorouracil for gastric cancer: results of a randomized trial. $\mathrm{Br} \mathbf{J}$ Cancer. 1999;80:269-72.

10. Cervantes A, Villar-Grimalt A, Abad A, Antón-Torres A, Belón J, Dorta J, et al. 5-Fluorouracil, folinic acid, epidoxorubicin and cisplatin (FLEP) combination chemotherapy in advanced measurable gastric cancer. A phase II trial of the Spanish Cooperative Group for Gastrointestinal Tumor Therapy (TTD). Ann Oncol. 1993;4:753-7.

11. Cocconi G, Bella M, Zironi S, Algeri R, Di Costanzo F, De Lisi $\mathrm{V}$, et al. Fluorouracil, doxorubicin, and mitomycin combination versus PELF chemotherapy in advanced gastric cancer: a prospective randomized trial of the Italian Oncology Group for Clinical Research. J Clin Oncol. 1994;12:2687-93.

12. Cocconi G, Carlini P, Gamboni A, Gasperoni S, Rodinò C, Zironi $\mathrm{S}$, et al. Cisplatin, epirubicin, leucovorin and 5-fluorouracil (PELF) is more active than 5-fluorouracil, doxorubicin and methotrexate (FAMTX) in advanced gastric carcinoma. Ann Oncol. 2003;14:1258-63.

13. Ajani JA. Optimizing docetaxel chemotherapy in patients with cancer of the gastric and gastroesophageal junction. Evolution of the docetaxel, cisplatin, and 5-fluorouracil regimen. Cancer. 2008;113:945-55.

14. Sulkes A, Smyth J, Sessa C, Dirix LY, Vermorken JB, Kaye S, et al. Docetaxel (Taxotere) in advanced gastric cancer: results of a phase II clinical trial. EORTC Early Clinical Trials Group. Br J Cancer. 1994;70:380-3.

15. Einzig AI, Neuberg D, Remick SC, Karp DD, O'Dwyer PJ, Stewart JA, et al. Phase II trial of docetaxel (Taxotere) in patients with adenocarcinoma of the upper gastrointestinal tract previously untreated with cytotoxic chemotherapy: the Eastern Cooperative Oncology Group (ECOG) results of protocol E1293. Med Oncol. 1996;13:87-93.

16. Mavroudis D, Kourousis C, Androulakis N, Kalbakis K, Agelaki $\mathrm{S}$, Kakolyris $\mathrm{S}$, et al. Frontline treatment of advanced gastric cancer with docetaxel and granulocyte colony-stimulating factor (G-CSF): a phase II trial. Am J Clin Oncol. 2000;23:341-4.

17. Bang YJ, Kang WK, Kang YK, Kim HC, Jacques C, Zuber E, et al. Docetaxel $75 \mathrm{mg} / \mathrm{m}^{2}$ is active and well tolerated in patients with metastatic or recurrent gastric cancer: a phase II trial. Jpn J Clin Oncol. 2002;32:248-54.

18. Roth AD, Maibach R, Martinelli G, Fazio N, Aapro MS, Pagani $\mathrm{O}$, et al. Docetaxel (Taxotere)-cisplatin (TC): an effective drug combination in gastric carcinoma. Swiss Group for Clinical Cancer Research (SAKK), and the European Institute of Oncology (EIO). Ann Oncol. 2000;11:301-6.

19. Fahlke J, Ridwelski K, Schmidt C, Hribaschek K, Stuebs P, Kettner E, et al. A multicentre phase II study of docetaxel plus cisplatin for the treatment of advanced gastric cancer. Chemotherapy. 2007;53(6):454-60.
20. Kim KH, Jeung KJ, Kim HJ, Bae SB, Kim CK, Lee NS, et al. Phase II study of docetaxel and cisplatin as first-line chemotherapy in patients with recurrent or metastatic gastric cancer. Cancer Res Treat. 2007;39(2):49-53.

21. Roth AD, Maibach R, Fazio N, Sessa C, Stupp R, Morant R, et al. 5-Fluorouracil as protracted continuous intravenous infusion can be added to full-dose docetaxel (Taxotere ${ }^{\circledR}$ )-cisplatin in advanced gastric carcinoma: a phase I-II trial. Ann Oncol. 2004;15:759-64.

22. Roth DA, Fazio N, Stupp R, Falk S, Bernhard J, Saletti P, et al. Docetaxel, cisplatin, and fluorouracil; docetaxel and cisplatin; and epirubicin, cisplatin, and fluorouracil as systemic treatment for advanced gastric carcinoma: a randomized phase II trial of the Swiss Group for Clinical Cancer Research. J Clin Oncol. 2007;25:3217-23.

23. Ajani JA, Fodor MB, Tjulandin SA, Moiseyenko VM, Chao Y, Filho SC, et al. Phase II multi-institutional randomized trial of docetaxel plus cisplatin with or without fluorouracil in patients with untreated, advanced gastric, or gastroesophageal adenocarcinoma. J Clin Oncol. 2005;23:5660-7.

24. Van Cutsem E, Moiseyenko MV, Tjulandin S, Majlis A, Constenla M, Boni C, et al. Phase III study of docetaxel and cisplatin plus fluorouracil compared with cisplatin and fluorouracil as firstline therapy for advanced gastric cancer: a report of the V325 study group. J Clin Oncol. 2006;24:4991-7.

25. Ajani JA, Moiseyenko VM, Tjulandin S, Majlis A, Constenla M, Boni C, et al. Quality of life with docetaxel plus cisplatin and fluorouracil compared with cisplatin and fluorouracil from a phase III trial for advanced gastric or gastroesophageal adenocarcinoma: the V-325 study group. J Clin Oncol. 2007;25: 3210-6.

26. de Gramont A, Krulik M, Cady J, Lagadec B, Maisani JE, Loiseau JP, et al. High-dose folinic acid and 5-fluorouracil bolus and continuous infusion in advanced colorectal cancer. Eur J Cancer Clin Oncol. 1988;24:1499-503.

27. de Gramont A, Bosset JF, Milan C, Rougier P, Bouché O, Etienne $\mathrm{PL}$, et al. Randomized trial comparing monthly low-dose leucovorin and fluorouracil bolus with bimonthly high dose leucovorin and fluorouracil bolus plus continuous infusion for advanced colorectal cancer: a French intergroup study. J Clin Oncol. 1997;14:808-15.

28. Louvet C, De Gramont A, Demuynck B, Nordlinger B, Maisani JE, Lagadec B, et al. High-dose folinic acid, 5-fluorouracil bolus and continuous infusion in poor-prognosis patients with advanced measurable gastric cancer. Ann Oncol. 1991;2(3):229-30.

29. Mitry E, Taïeb J, Artru P, Boige V, Vaillant JN, Clavero-Fabri $\mathrm{MC}$, et al. Combination of folinic acid, 5-fluorouracil bolus and infusion, and cisplatin (LV5FU2-P regimen) in patients with advanced gastric and gastroesophageal junction carcinoma. Ann Oncol. 2004; 15:765-9.

30. Bouché O, Raoul JL, Bonnetain F, Giovannini M, Etienne PL, Lledo $\mathrm{G}$, et al. Randomized multicenter phase II trial of a biweekly regimen of fluorouracil and leucovorin (LV5FU2), LV5FU2 plus cisplatin, or LV5FU2 plus irinotecan in patients with previously untreated metastatic gastric cancer: a Fédération Francophone de Cancérologie Digestive Group Study-FFCD 9803. J Clin Oncol. 2004;22:4319-28.

31. Yilmaz U, Oztop I, Alacacioglu A, Yaren A, Tarhan O, Somali I. Irinotecan combined with infusional 5-fluorouracil and high-dose leucovorin for the treatment of advanced gastric carcinoma as the first-line chemotherapy. Chemotherapy. 2006;52:264-70.

32. Cascinu S, Baldelli AM, Catalano V, Giordani P, Beretta GD, Silva RR, et al. Infusional 5-fluorouracil, cisplatin and mitomycin $\mathrm{C}$ in advanced gastric cancer: a low cost effective regimen. Br J Cancer. 2002;86:213-7.

33. Felici A, Carlini P, Ruggeri EM, Gamucci T, Pollera CF, De Marco S, et al. Bi-weekly chemotherapy with cisplatin, 
epirubicin, folinic acid and 5-fluorouracil continuous infusion plus G-CSF in advanced gastric cancer: a multicentric phase II study. Cancer Chemother Pharmacol. 2006;57:59-64.

34. Tomasello G, Chiesa MD, Buti S, Brighenti M, Negri F, Rovere RK, et al. Dose-dense chemotherapy in metastatik gastric cancer with a modified docetaxel-cisplatin-5-fluorouracil regimen. Tumori. 2010;96:48-53.

35. Shah MA, Shibata S, Stoller RG, Kemeny M, Ritch PS, Krishnamurthi SS, et al. Random assignment multicenter phase II study of modified docetaxel, cisplatin, fluorouracil ( $\mathrm{mDCF}$ ) versus DCF with growth factor support (GCSF) in metastatic gastroesophageal adenocarcinoma (GE). J Clin Oncol 2010;28(Suppl):15s (abstract 4014).

36. Ben Aharon I, Purim O, Kundel Y, Brenner R, Gordon N, Sulkes $\mathrm{A}$, et al. The combination of docetaxel, cisplatin, and 5-fluorouracil in advanced gastric cancer: a single-institution experience. Anti-Cancer Drugs. 2012. doi:10.1097/CAD.0b013e32834fd780.

37. Lorenzen S, Hentrich M, Haberl C, Heinemann V, Schuster T, Seroneit T, et al. Split-dose docetaxel, cisplatin and leucovorin/ fluorouracil as first line therapy in advanced gastric cancer and adenocarcinoma of the gastroesophageal junction: results of a phase II trial. Ann Oncol. 2007;18:1673-9.

38. Park SR, Chun JH, Kim YW, Lee JH, Choi IJ, Kim CG, et al. Phase II study of low-dose docetaxel/fluorouracil/cisplatin in metastatic gastric carcinoma. Am J Clin Oncol. 2005;28:433-8.

39. Oh DY, Kim TY, Kwon JH, Lee JJ, Joh Y, Kim DW, et al. Docetaxel +5 -fluorouracil + cisplatin 3-day combination chemotherapy as a first-line treatment in patients with unresectable gastric cancer. Jpn J Clin Oncol. 2005;35(7):380-5.

40. Chi YHBL, Ren JH, Yang L, Cui CX, Li JL, Wang JW. Phase II clinical study on the modified DCF regimen for treatment of advanced gastric carcinoma. Chin Med J. 2011;124(19):2997-3002.

41. Inal A, Kaplan MA, Kucukoner M, Isikdogan A. Docetaxel and cisplatin plus fluorouracil compared with modified docetaxel, cisplatin, and 5-fluorouracil as first-line therapy for advanced gastric cancer: a retrospective analysis of single institution. Neoplasma. 2012;59(2):233-6.

42. Ozdemir NY, Abali H, Oksuzoglu B, Budakoglu B, Uncu D, Guler T, et al. The efficacy and safety of reduced-dose docetaxel, cisplatin, and 5-fluorouracil in the first-line treatment of advanced stage gastric adenocarcinoma. Med Oncol. 2010;27:680-4.

43. Kang SH, Kim JI, Goh PG, Hwang SW, Kwon DS, Nam KW, et al. Docetaxel-cisplatin-5-FU combination chemotherapy as a first-line treatment in patients with metastatic or recurred gastric cancer. Korean J Gastroenterol. 2007;50(3):157-63.

44. Tebbutt NC, Cummins MM, Sourjina T, Strickland A, Van Hazel G, Ganju V, et al. Randomised, non-comparative phase II study of weekly docetaxel with cisplatin and 5-fluorouracil or with capecitabine in oesophagogastric cancer: the AGITG ATTAX trial. Br J Cancer. 2010;102:475-81.

45. Overman MJ, Kazmi SM, Jhamb J, Lin E, Yao JC, Abbruzzese JL, et al. Weekly docetaxel, cisplatin, and 5-fluorouracil as initial therapy for patients with advanced gastric and esophageal cancer. Cancer (Phila). 2010;116:1446-53. 